\title{
Efeito de níveis crescentes de ureia na alimentação de vacas sobre o rendimento, composição, perfil de ácidos graxos e sensorial do queijo minas frescal*
}

\section{Effect of increasing levels of urea in cows feed on yield, composition, fatty acid profile and sensory of minas fresh cheese}

\author{
Vanice Mendes de Souza, ${ }^{* *}$ Luciana Albuquerque Caldeira, ${ }^{* * *}$ Vicente Ribeiro Rocha Júnior, ${ }^{* * *}$ Ana Paula da Silva Antunes, ${ }^{* *}$ \\ José Reinaldo Mendes Ruas, ${ }^{* * * *}$ Pedro Felipe Santana, ${ }^{* * * * *}$ Natanael Mendes Costa, ${ }^{* \star * * *}$ Lucas Daniel Alcântara Borges ${ }^{\star * * * * *}$
}

\begin{abstract}
Resumo
O estudo teve como objetivo avaliar a qualidade do queijo minas frescal processado com leite de vacas alimentadas com dietas com níveis crescentes de ureia (0;33\%; 66\% e 100\%, que corresponderam a 0, 0,92, 1,84 e 2,77\% de PB na forma de NNP) em substituição ao farelo de soja. Foram utilizadas oito vacas F1 Holandês x Zebu, primíparas, com aproximadamente 150 dias de lactação ao início do experimento e produção média de $10 \mathrm{~kg}$ de leite corrigido para $3,5 \%$ de gordura dia-1 ${ }^{-1}$, em dois quadrados latinos $4 \times 4,4$ animais, 4 dietas e 4 períodos experimentais. As amostras de leite de cada vaca, da ordenha da manhã e da tarde, foram coletadas e analisadas quanto à composição físico-química. No terceiro dia de coleta, o leite obtido de cada tratamento foi processado para fabricação do queijo minas frescal. Os produtos foram analisados quanto às suas características físico-químicas, textura, rendimento, perfil de ácidos graxos, e aceitação sensorial. Não houve efeito da adição dos níveis crescentes de ureia em substituição ao farelo de soja na dieta das vacas para todos os parâmetros que indicam a qualidade dos queijos analisados. Dessa forma, conclui-se que a substituição total da ureia pelo farelo de soja na dieta com o intuito de reduzir custo de alimentação não altera a qualidade na produção do queijo minas frescal.
\end{abstract}

Palavras-chave: farelo de soja, gordura, nitrogênio não proteico, proteína.

\begin{abstract}
The study aimed to evaluate the quality of the minas fresh cheese processed with milk cows fed diets with increasing levels of urea $(0,33 \%, 66 \%$ and $100 \%$, corresponding to $0,0.92,1.84$ and $2.77 \%$ crude protein in the form of NPN) replacing soybean meal. Eight cows F1 Holstein $\times$ Zebu, gilts, with approximately 150 days of lactation to the beginning of the experiment and average production of $10 \mathrm{~kg}$ of milk corrected to $3.5 \%$ fat day-1, in two Latin squares $4 \times 4,4$ animals, 4 diets and 4 experimental periods. Samples of milk from each cow, the milking morning and afternoon, were collected and analyzed for physical and chemical composition. On the third day of collection, the milk obtained from each treatment was processed for the production of minas fresh cheese. Products were analyzed as to their physical and chemical characteristics, texture, yield, fatty acid profile, and sensory acceptance. There was no effect of the addition of increasing levels of urea in substitution of soybean meal in the diet of cows to all the parameters that indicate the quality of cheeses analyzed. Thus, it is concluded that the total replacement of soybean meal by urea in order to reduce power cost does not change the quality in the production of minas fresh cheese.
\end{abstract}

Keywords: soybean meal, fat, non-protein nitrogen, protein.

\section{Introdução}

O valor nutritivo do leite e dos derivados lácteos, no que destaca a qualidade tecnológica na produção de queijos, apresentam parâmetros na composição físico-química que são grandemente influenciados pela nutrição da vaca (Fernandes et al., 2008; Nudda et al., 2014).

A utilização de ureia (nitrogênio não protéico (NNP)) na dieta de vacas leiteira, como fonte de nitrogênio degradável no rúmen, em substituição parcial ao farelo de soja, é uma estratégia nutricional bastante comum no Brasil e visa à redução dos custos com alimentação, sem alteração da produção de leite. O NNP pode alterar a composição da proteína do leite, influenciando o processamento industrial da matéria-prima, já que os teores de proteína verdadeira e da caseína têm influência direta sobre a fabricação do queijo (Aquino et al., 2009).

O queijo minas frescal é um derivado do leite, que contém em sua composição mais de $20 \%$ de gordura, e uma das

*Recebido em 22 de outubro de 2014 e aceito em 13 de julho de 2015.

**Aluna Programa de Pós-Graduação em Zootecnia da Unimontes, Campus de Janaúba/MG, Brasil.

${ }^{* * *}$ Professor da Universidade Estadual de Montes Claros, Campus de Janaúba/MG, Brasil.

****Professor da Universidade Estadual de Montes Claros, Campus de Janaúba/MG, Brasil; Bolsista de Produtividade em Pesquisa do CNPq e FAPEMIG.

*****Pesquisador da EPAMIG, Nova Porterinha/MG, Brasil; Bolsistas de Produtividade em Pesquisa do CNPq.

******Acadêmicos do Curso de Graduação em Zootecnia da Unimontes, Campus de Janaúba/MG, Brasil.

Autor para correspondência: vicente.rocha@unimontes.br. 
características do leite bovino é a grande quantidade de ácidos graxos saturados provenientes da síntese de novo que ocorre na glândula mamária, sendo que esses ácidos graxos têm sido associados à elevação dos níveis de colesterol e ao risco de doenças cardíacas (Fernandes et al., 2008). Segundo Benchaar et al. (2007), o perfil de ácidos graxos no leite pode ser alterado por modificações no padrão de fermentação ruminal e espécies de bactérias ruminais. Supõe-se que a substituição da proteína verdadeira na dieta das vacas pelo nitrogênio não proteico poderia alterar o equilíbrio da microbiota ruminal e consequentemente o perfil da fermentação ruminal e dos ácidos graxos que chegam ao duodeno. De acordo com Vlaeminck et al. (2006), parte dos ácidos graxos que compõem a gordura do leite vêm da absorção intestinal de lipídeos de membrana provenientes das bactérias do rúmen.

Dessa forma, o objetivo do estudo foi avaliar a composição físico-química, rendimento e aceitação sensorial, assim como o perfil de ácidos graxos do queijo minas frescal obtido do leite de vacas $\mathrm{F} 1$ Holandês $\mathrm{x}$ Zebu alimentadas com dietas com níveis crescentes de ureia em substituição parcial e total ao farelo de soja.

\section{Material e métodos}

O experimento foi conduzido na Fazenda Experimental da Universidade Estadual de Montes Claros - UNIMONTES, localizada no Município de Janaúba/MG. Foram utilizadas 8 vacas F1 Holandês x Zebu, primíparas, com período de lactação, ao início do experimento, de 150 dias \pm 12 dias. As dietas foram formuladas para ser isoproteicas, conforme o NRC (2001) para atender o potencial de vacas com média de $450 \mathrm{~kg}$ de peso corporal e produção média de $10 \mathrm{~kg}$ de leite corrigido para $3,5 \%$ de gordura dia $^{-1}$, sendo fornecidas para as vacas duas vezes ao dia, às $8 \mathrm{~h}$ e às $16 \mathrm{~h}$.

O delineamento experimental adotado foram dois quadrados latinos $4 \times 4$, composto, cada um, de quatro animais, quatro tratamentos e quatro períodos experimentais. Foram utilizadas 4 dietas experimentais, com níveis crescentes de ureia em substituição do farelo de soja nos concentrados, 0; 33\%; $66 \%$ e $100 \%$, que corresponderam a $0 ; 0,92 ; 1,84$ e $2,77 \%$ de PB na forma de NNP. O experimento teve duração de 72 dias, dividido em quatro períodos de 18 dias, os primeiros 15 dias de cada período foram reservados para adaptação dos animais às dietas e os três últimos dias para coleta de dados e amostras.

O volumoso das dietas foi a silagem de sorgo, sendo esta pesada diariamente, distribuída nos cochos e misturada com os concentrados de cada tratamento. As sobras do cocho foram pesadas e registradas e as quantidades fornecidas das dietas experimentais foram ajustadas de acordo com as sobras, mantendo a mesma relação volumoso:concentrado (80:20) com base na matéria seca, de forma que as sobras representassem $10 \%$ da quantidade fornecida. A proporção dos ingredientes utilizados nas dietas e a composição química das mesmas encontram-se na Tabela 1.

Os animais foram ordenhados em ordenha mecânica, com bezerro ao pé, duas vezes ao dia. Nos últimos três dias de cada período foram coletadas as amostras de leite, sendo feito um pool das amostras do leite da ordenha da manhã e da tarde, proporcional à quantidade de leite produzido diariamente.
Tabela 1: Proporção de ingredientes e composição química das dietas experimentais (\%) na base da matéria seca $(\%)$

\begin{tabular}{lcccc}
\hline \multicolumn{4}{c}{ Composição em ingredientes (\%MS) } \\
\hline \multicolumn{5}{c}{ Níveis crescentes de PB na } \\
& 0 & 0,92 & 1,84 & 2,77 \\
\cline { 2 - 5 } Ingredientes & 80 & 80 & 80 & 80 \\
\hline Silagem de sorgo & 6,74 & 4,49 & 2,24 & 0 \\
Farelo de soja & 12,26 & 14,14 & 16,02 & 17,9 \\
Milho moído & 0 & 0,36 & 0,73 & 1,1 \\
Ureia:sulfato de amônia (9:1) & 1 & 1 & 1 & 1 \\
Suplemento mineral & Composição química & & \\
\hline & 46,72 & 46,71 & 46,67 & 46,05 \\
\hline Matéria seca (\%) & 93,28 & 93,31 & 93,4 & 93,54 \\
Matéria orgânica (\%) & 9,84 & 9,86 & 9,89 & 9,92 \\
Proteína bruta (\%) & 0,45 & 0,43 & 0,5 & 0,48 \\
NIDN (\%) & 0,025 & 0,024 & 0,028 & 0,027 \\
NIDA (\%) & 1,84 & 1,85 & 1,86 & 1,86 \\
Extrato etéreo (\%) & 81,61 & 81,43 & 81,25 & 82,05 \\
Carboidratos totais (\%) & 27,41 & 27,03 & 27,17 & 27,14 \\
Carboidrato não fibroso (\%) & 55,97 & 55,9 & 55,83 & 55,77 \\
Fibra em detergente neutro (\%) & 54,2 & 54,4 & 54,08 & 54,91 \\
FDNcp (\%) & 31,75 & 31,63 & 31,5 & 31,37 \\
Fibra em detergente ácido (\%) & 3,17 & 3,15 & 3,12 & 3,10 \\
Lignina (\%) & 65,0 & 65,58 & 65,18 & 64,68 \\
Nutrientes digestíveis totais (\%) & & & & \\
\hline
\end{tabular}

NIDN = nitrogênio insolúvel em detergente neutro; NIDA = nitrogênio insolúvel em detergente ácido; $\mathrm{FDNc}_{\mathrm{p}}=$ Fibra em detergente neutro corrigida para cinza e proteína; $\mathrm{PB}=$ Proteína bruta; NNP = Nitrogênio não proteico; ${ }^{1} \mathrm{NRC}$ (2001).

Posteriormente essas amostras foram encaminhadas refrigeradas ao Laboratório de Tecnologia de Produtos de Origem Animal da Unimontes - Campus de Janaúba e armazenadas a $5^{\circ} \mathrm{C}$ para caracterização físico-química, no mesmo dia.

Para determinação das características físico-químicas do leite (Tabela 2), foram realizadas as seguintes análises, em triplicata: acidez titulável ( $\left.{ }^{\circ} \mathrm{D}\right)$ expressa em porcentagem de ácido lático, pelo percentual de ácido presente na amostra por titulação com $\mathrm{NaOH} 0,1 \%$, ; pH por meio do potenciômetro modelo TECNOPON; densidade $(\mathrm{g} / \mathrm{mL})$ a $15{ }^{\circ} \mathrm{C}$, pelo termolactodensímetro de Quevenne; percentual de gordura, pelo método de Gerber; teor de proteína pelo método kjeldahl; cinzas pela incineração na mufla a $550^{\circ} \mathrm{C}$ e índice crioscópico ( $\left.{ }^{\circ} \mathrm{H}\right)$, utilizando crioscópio eletrônico modelo LAKTRON 312-L. A porcentagem de lactose foi calculada pela diferença entre os constituintes sólidos (proteína, gordura e cinzas). O cálculo do extrato seco total (EST) foi obtido por meio da fórmula \% ES = $1,2 \times \mathrm{Gd}+2,665 \times(\mathrm{D}-1)$, proposta por Fleishmann, e o extrato seco desengordurado (ESD) pela subtração do teor de gordura (Brasil, 2006). 
Tabela 2: Composição físico-química do leite utilizado para o processamento do queijo minas Frescal, a partir de cada dieta experimental

\begin{tabular}{lcccc}
\hline & \multicolumn{4}{c}{ Níveis crescentes de PB na forma } \\
\cline { 2 - 5 } Variáveis & 0 & 0,92 & 1,84 & 2,77 \\
\hline Densidade a $15^{\circ} \mathrm{C}$ & 1,031 & 1,031 & 1,031 & 1,030 \\
Índice crioscópico $\left({ }^{\circ} \mathrm{D}\right)$ & $-0,541$ & $-0,542$ & $-0,540$ & $-0,543$ \\
Gordura (\%) & 3,47 & 3,68 & 3,46 & 3,48 \\
Proteína (\%) & 3,43 & 3,46 & 3,36 & 3,29 \\
Lactose (\%) & 4,74 & 4,67 & 4,72 & 4,85 \\
EST (\%) & 14,14 & 14,2 & 13,99 & 13,97 \\
ESD (\%) & 9,15 & 9,21 & 9,09 & 9,03 \\
Resíduo mineral fixo (\%) & 0,8 & 0,79 & 0,79 & 0,8 \\
\hline
\end{tabular}

EST= Extrato Seco Total; ESD= Extrato Seco Desengordurado; NNP = Nitrogênio Não Proteico;

O leite de cada dieta experimental foi pesado, filtrado e submetido à pasteurização lenta $\left(65^{\circ} \mathrm{C}\right.$ por $\left.30 \mathrm{~min}\right)$ para fabricação do queijo minas frescal, sendo resfriado a $39^{\circ} \mathrm{C}$ para adição do cloreto de cálcio $(40 \mathrm{~mL} / 100 \mathrm{~L})$ e o coalho $(30 \mathrm{~mL} / 100 \mathrm{~L})$, este diluído em parte igual de água filtrada. Após um tempo de 50 min ocorreu a coagulação do leite. Em seguida, foi realizado o corte da massa com uma faca inox em cubos de 1,5 a $2 \mathrm{~cm}$, intercalando a mexedura e o repouso para promover a dessoragem, seguida da drenagem do soro. Posteriormente, a massa foi colocada em fôrmas plásticas e procedeu-se à salga $(700 \mathrm{~g} / 100 \mathrm{~L}$ de sal branco refinado). Os queijos foram resfriados numa temperatura de $4^{\circ} \mathrm{C}$ por aproximadamente 12 horas. Em seguida, foram embalados e pesados. A qualidade dos queijos foi analisada pelos parâmetros de composição físico-químicas, análise de textura, rendimento, perfil de ácidos graxos, microbiológicas e de aceitação sensorial.

A textura das amostras de queijo foi determinada utilizando-se um Texturômetro - Modelo TAXT da Stabic Micro Systems, com auxílio de um software, fornecendo diretamente a força de corte (kgf). Foi utilizada uma célula do tipo Probe Warner Bratzler.

O rendimento bruto dos queijos foi calculado segundo a equação (Andreatta et al., 2009): Rendimento bruto $(\mathrm{kg} / \mathrm{kg})=$ peso da formulação (leite mais os ingredientes) $(\mathrm{kg}) /$ massa de queijo após embalagem $(\mathrm{kg})$. O rendimento ajustado (REAJ) para o teor de umidade do queijo (Lucey e Kelly, 1994) foi calculado considerando-se um valor de $57 \%$ como referência para a umidade do queijo minas frescal, conforme a equação sugerida por Oliveira (1986): REAJ (kg/kg) = Rendimento bruto x $(100$ - \% umidade atual $) / 57$.

Para determinação das características físico-químicas do queijo, foram realizadas as seguintes análises, em triplicata: acidez titulável $\left({ }^{\circ} \mathrm{D}\right)$ expressa em porcentagem de ácido lático, pelo porcentual de ácido presente na amostra por titulação com $\mathrm{NaOH} 0,1 ; \mathrm{pH}$ por meio do potenciômetro modelo-TECNOPON; porcentual de gordura, pelo método de Gerber; teor de proteína pelo método kjeldahl; resíduo mineral fixo, pela eliminação da matéria orgânica à temperatura de $550^{\circ} \mathrm{C}$, sólidos totais através da evaporação de água da amostra com utilização da estufa a $105^{\circ} \mathrm{C}$, umidade determinada pela subtração dos sólidos totais
(Brasil, 2006) e atividade de água (Aw) por meio de medidor de Aw modelo AQUA LAB.

O perfil de ácidos graxos dos queijos foi analisado após extração, segundo Hara (1978), e metilação de acordo com a metodologia descrita por Christie (1982). As amostras transmetiladas foram analisadas em cromatógrafo a gás modelo FOCUS CG-FINNIGAN, com detector de ionização de chama, coluna capilar CP-Sil 88 (Varian), com $100 \mathrm{~m}$ de comprimento por $0,25 \mu \mathrm{m}$ de diâmetro interno e $0,20 \mu \mathrm{m}$ de espessura do filme. Os ácidos graxos foram identificados por comparação dos tempos de retenção dos ésteres metílicos das amostras com padrões de ácidos graxos de manteiga. Os ácidos graxos foram quantificados por normalização das áreas dos ésteres metílicos. Os resultados dos ácidos graxos foram expressos em $\mathrm{mg} / \mathrm{g}$ de gordura. A determinação do perfil de ácidos graxos foi realizada no Laboratório de Nutrição Animal da ESALQ-USP _ Campus Piracicaba.

A qualidade nutricional da fração lipídica foi avaliada pelos dados de composição em ácidos graxos, empregando-se os seguintes cálculos: Índice de Aterogenecidade $(\mathrm{IA})=\{(\mathrm{C} 12: 0+(4 \times \mathrm{C} 14: 0)$

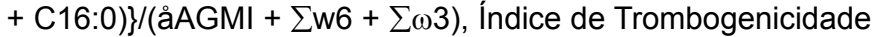
$(I T)=(C 14: 0+C 16: 0+C 18: 0) /\left\{(0,5 \times\right.$ åAGMI $)+\left(0,5 \times \sum w 6\right.$ $\left.+\left(3 \times \sum \omega 3\right)+\left(\sum \omega 3 / \sum w 6\right)\right\}$, razão entre ácidos graxos hipercolesterolêmicos e hipocolesterolêmicos $(\mathrm{HH})=(\mathrm{C} 14: 0+$ C16:0) / (monoinsaturado + poliinsaturado), razão entre ácidos graxos poli-insaturados e ácidos graxos saturados e razão entre w6 e $\omega 3$, segundo Ulbricth e Southage (1991) e Ácidos Graxos Desejáveis $(A G D)=($ insaturados + C18:0) segundo Costa et al. (2008).

As análises microbiológicas dos queijos foram realizadas no Laboratório de Tecnologia de Produtos de Origem Animal da UNIMONTES - Campus Janaúba. No laboratório, as amostras de queijo foram submetidas à limpeza externa das embalagens com álcool $70 \%$ para remoção dos contaminantes presentes. A determinação do NMP (número mais provável) de coliformes a $35^{\circ} \mathrm{C}$ foi realizada a partir da diluição $10^{-1}$ para então serem transferidas alíquotas de $1 \mathrm{ml}$ para tubos de ensaio contendo tubos de Durhan invertidos, imersos em caldo lauril triptose. As amostras foram incubadas a $35^{\circ} \mathrm{C}$ por 48 horas. Para confirmação da presença de coliformes totais, foi realizada a inoculação dos tubos positivos em caldo verde brilhante. A confirmação da presença de coliformes a $45^{\circ} \mathrm{C}$ foi realizada por meio da inoculação em caldo E. coli, a partir de tubos positivos na análise de coliformes totais, com incubação em temperatura seletiva de $45^{\circ} \mathrm{C}$ por 48 horas. A contagem de micro-organismos mesófilos foi realizada transferindo-se alíquota de $1 \mathrm{~mL}$ das diluições obtidas para placas de Petri contendo ágar-padrão para Contagem (PCA), incubados a $35^{\circ} \mathrm{C}$ por 48 horas. Os resultados foram expressos em NMP de coliformes a $35^{\circ} \mathrm{C}$, coliformes a $45^{\circ} \mathrm{C}$ e mesófilos por grama, conforme Silva et al. (2010).

A análise sensorial foi realizada no Laboratório de Tecnologia de Produtos de Origem Animal da UNIMONTES - Campus Janaúba. A avaliação dos queijos pelos julgadores não treinados foi realizada por meio do teste de aceitação sensorial descrito por Meilgaard et al. (1999). A análise sensorial do queijo foi feita em quatro períodos, com 30 provadores por período. As amostras foram codificadas e cortadas em cubos, com peso de $25 \mathrm{~g}$, e fornecidas em copinhos descartáveis. As amostras, com seus respectivos códigos, foram servidas simultaneamente e classificadas pelos provadores para avaliação da aceitação geral 
do mesmo, dando-se a nota de valor 1 para a menos aceita e 9 para a mais aceita. Os dados foram avaliados calculando-se a diferença mínima significativa (DMS) da soma de ordens de cada amostra de acordo com o Método de Friedman, com nível de significância de 5 \% (Meilgaard et al., 1999).

Em função da população de micro-organismo ser classificada como uma variável quantitativa discreta, resultante de dados de contagem, foi realizada a transformação logarítmica [Log $(\mathrm{X}+1)$ ]. Testou-se, através do procedimento GLM (General Linear Models) do SAS (SAS INSTITUTE, 2004), a aditividade através da análise de covariância dos valores preditos ao quadrado, obtendo-se $\mathrm{P}=0,8049$; a normalidade através do procedimento univariate, com a estatística W (Shapiro-Wilk), com $\mathrm{P}=0,3052$ e a homogeneidade de variância pelo teste de Barthett $(P=0,9925)$. Uma vez confirmada a não significância destes testes, os dados da população de micro-organismos, além daqueles relativos às características físico-químicas, perfil de ácidos graxos e índices nutricionais do queijo foram submetidos à análise de variância e quando o teste de $\mathrm{F}$ foi significativo, as médias de tratamentos foram comparadas pelo teste de Dunnett, ao nível de $5 \%$ de probabilidade, com o tratamento controle. O efeito dos níveis de ureia foi avaliado por meio de regressão, ao nível de $5 \%$ de probabilidade. A análise foi realizada com o software estatístico SAS (SAS INSTITUTE, 2004).

\section{Resultados e discussão}

Como observado na Tabela 3, a composição físico-química, rendimento e textura dos queijos minas frescal não foram influenciados pelos níveis de ureia em substituição ao farelo de soja na dieta das vacas. Certamente, a substituição da proteína verdadeira do farelo de soja pelo NNP (ureia), não comprometeu a síntese microbiana no rúmen e a utilização dos nutrientes da dieta, não alterando a composição e qualidade do leite (Tabela

Tabela 3: Composição físico-química, textura e rendimento do queijo Minas frescal obtido do leite de vacas F1 Holandês $x$ Zebu alimentadas com dietas contendo níveis crescentes de ureia, coeficientes de

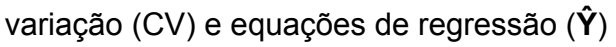

\begin{tabular}{|c|c|c|c|c|c|c|}
\hline \multirow[b]{2}{*}{ Variáveis } & \multicolumn{4}{|c|}{$\begin{array}{l}\text { Níveis crescentes de PB na } \\
\text { forma de NNP }(\%)\end{array}$} & \multirow[b]{2}{*}{$\mathrm{CV}(\%)$} & \multirow[b]{2}{*}{$\hat{\mathrm{Y}}$} \\
\hline & 0 & 0,92 & 1,84 & 2,77 & & \\
\hline $\mathrm{pH}$ & 6,65 & 6,55 & 6,5 & 6,52 & 1,14 & 6,56 \\
\hline Aw & 0,98 & 0,98 & 0,98 & 0,98 & 0,64 & 0,98 \\
\hline Ácido láctico (\%) & 0,07 & 0,05 & 0,06 & 0,05 & 15,14 & 0,06 \\
\hline Gordura (\%) & 16,45 & 16,53 & 16,53 & 17,47 & 5,48 & 16,75 \\
\hline Proteína (\%) & 14,17 & 15,13 & 13,51 & 14,06 & 11,07 & 14,22 \\
\hline Umidade (\%) & 57,27 & 58,13 & 56,16 & 56 & 2,07 & 56,88 \\
\hline ST (\%) & 42,74 & 41,87 & 43,84 & 44,01 & 2,74 & 43,12 \\
\hline Resíduo mineral fixo (\%) & 3,22 & 2,63 & 2,55 & 2,37 & 13,41 & 2,69 \\
\hline Rendimento bruto $(\mathrm{kg} / \mathrm{kg})$ & 5,13 & 5,21 & 4,71 & 4,61 & 6,1 & 4,91 \\
\hline Rendimento ajustado $(\mathrm{kg} / \mathrm{kg})$ & 3,84 & 3,83 & 3,62 & 3,56 & 8,04 & 3,71 \\
\hline Textura (kgf) & 3,3 & 4,0 & 4,6 & 3,8 & 15,86 & 3,9 \\
\hline
\end{tabular}

$\mathrm{ST}=$ Sólidos totais; $\mathrm{Aw}=$ Atividade de água.
2) utilizado para fabricação do queijo. Os resultados encontrados neste trabalho estão de acordo com os obtidos por Aquino et al. (2009), que utilizando até $1,5 \%$ de ureia na dieta de vacas em meio da lactação, substituindo parcialmente o farelo de soja e com produção média de $22 \mathrm{~kg}$ de leite dia ${ }^{-1}$, não verificaram alteração na composição do leite e do queijo.

Os valores de $\mathrm{pH}$ constatados neste trabalho, com média de 6,56 e concentração de ácido lático média de $0,06 \%$, indicam que os queijos produzidos apresentaram qualidade satisfatória, o que deve ser confirmado por meio de um teste de análise sensorial, que está diretamente relacionada com a aceitação do produto pelo consumidor. Além disso, esses resultados caracterizam o queijo minas frescal como sendo um queijo de sabor leve, pouco pronunciado e ligeira acidez.

Em relação aos teores de gordura do queijo, foi avaliado um percentual médio de $16,75 \%$. Valores relativamente superiores aos descritos por Aquino et al. (2009), que encontraram teores de gordura variando de 13,80 a $14,22 \%$ no queijo minas frescal, com uma produção média de leite corrigido para $3,5 \%$ de gordura de 21,04 kg dia-1 e Aguiar et al. (2013), que estudando consumo, produção e processamento do leite de vacas $7 / 8$ Holandês/Gir, com produção média de $28,15 \mathrm{~kg}$ de leite com $3,5 \%$ de gordura dia $^{-1}$, alimentadas com dietas à base de silagem de cana-deaçúcar (relação volumoso:concentrado 45:55), contendo níveis crescentes de ureia em substituição parcial ao farelo de soja $(0$; 0,$58 ; 1,17,1,75 \%$ na MS total da dieta), encontraram valores de gordura variando de 10,33 a $12,70 \%$. O maior teor de gordura constatado no queijo minas frescal deste estudo em relação aos verificados nos trabalhos supracitados, pode estar relacionado com o menor nível de produção de leite (10 kg de leite corrigido para $3,5 \%$ de gordura dia $^{-1}$ ) das vacas, que apresentaram uma variação de 3,46 a 3,68 \% de gordura no leite (Tabela 2).

Verificou-se neste estudo um percentual médio de proteína bruta no queijo minas frescal de $14,22 \%$. Como pode ser verificado na Tabela 2 , o percentual médio de PB no leite, considerando-se as quatro dietas experimentais, foi de $3,4 \%$. Segundo Aquino et al. (2009), os valores de proteína do leite são importantes, principalmente a caseína, pois tais concentrações afetam diretamente o rendimento na produção de queijos. Assim, pode-se dizer que as dietas avaliadas, associadas ao nível de produção e genética dos animais, proporcionaram boa concentração de proteína no leite (Tabela 2), e possivelmente, sem alteração nos teores de caseína, o que pode ter contribuído para o elevado rendimento bruto do queijo produzido, com valor médio de $4,91 \mathrm{~kg} / \mathrm{kg}$ e rendimento ajustado de $3,71 \mathrm{~kg} / \mathrm{kg}$. Dessa maneira, o uso do NNP em total substituição à proteína verdadeira do farelo de soja parece ser viável para vacas F1 Holandês $x$ Zebu nas condições do presente experimento, sob o ponto de vista do rendimento na fabricação de queijo minas frescal. Souza e Silva (2005) registraram rendimento bruto de $6,09 \mathrm{~kg} / \mathrm{kg}$ para o queijo minas frescal tradicional processado com coalho bovino, cujos valores médios foram maiores, o que significa um menor rendimento quando comparados com resultados encontrados no presente trabalho para todas as dietas avaliadas. 
A umidade do queijo foi em média de $56,66 \%$ (Tabela 3 ) e está de acordo com a legislação vigente (Brasil, 2004) para o queijo minas frescal, que deve apresentar mais de $55 \%$ de umidade. De acordo com os resultados obtidos para teor de umidade, os queijos podem ser classificados como queijo de "alta umidade". A Aw verificada neste trabalho confirma a alta umidade do queijo, visto que os valores médios encontrados para essa variável foram de 0,98 (Tabela 3).

As dietas analisadas não apresentaram efeito sobre os sólidos totais e nem sobre as concentrações do resíduo mineral fixo. Os teores de sólidos totais dos queijos, em média de 43,12 \% (Tabela 3) encontrados neste trabalho, são similares aos resultados relatados por Caruso (1997), que descreveram média de $45,18 \%$ de sólidos totais em queijos minas frescal e relatou tendência de aumento do teor de sólidos totais devido à pequena dessoragem que ocorre com o aumento do tempo de armazenamento.

Não houve efeito das dietas sobre a textura do queijo minas frescal (Tabela 3), indicando que o queijo produzido com o leite de vacas alimentadas com dietas contendo níveis crescentes de ureia em substituição ao farelo de soja pode ser considerado macio. Resultados de até 4,6 kgf correspondem à escala sensorial com uma maciez aceitável segundo Shackelford et at. (1991).

A composição percentual de ácidos graxos nos lipídios totais do queijo minas frescal obtido do leite de vacas F1 Holandês $x$ Zebu não diferiram entre si $(P>0,05)$ em função da substituição parcial e total do farelo de soja pela ureia na dieta (Tabela 4). Segundo Benchaar et al. (2007), o perfil de ácidos graxos no leite pode ser alterado por modificações no padrão de fermentação ruminal e espécies de bactérias ruminais. Sendo assim, poder-se-ia esperar que, com a modificação da fração nitrogenada da dieta, substituindose a proteína verdadeira do farelo de soja pelo NNP, as proporções das diferentes populações de espécies de bactérias ruminais poderiam ser alteradas, contribuindo com uma possível modificação no perfil de ácidos graxos que chega ao duodeno. De acordo com Vlaeminck et al. (2006), parte dos ácidos graxos que compõem a gordura do leite vem da absorção intestinal de lipídeos de membrana provenientes das bactérias do rúmen. Entretanto, para o nível de produção de leite avaliado (10 $\left.\mathrm{kg} \mathrm{dia}^{-1}\right)$, a magnitude da substituição do farelo de soja pela ureia (Tabela 1), certamente, não foi suficiente para influenciar de forma significativa o equilíbrio das populações de bactérias do rúmen.

O total de ácidos graxos saturados (AGS) foi de 75,42 \%, sendo que os maiores percentuais foram encontrados para os ácidos palmítico (16:0), com 38,15\%, e o ácido mirístico (C14:0), com $12,45 \%$. Segundo Dietschy (1998), esses ácidos graxos são considerados hipercolesterolêmicos, devido ao fato de esses isômeros demonstrarem menor ação sobre a atividade dos receptores hepáticos para a lipoproteína de baixa densidade (LDL), ou o mau colesterol, aumentando assim a LDL circulante no plasma sanguíneo. Outro ácido graxo saturado com relevante participação na gordura do leite foi o esteárico (C18:0) com 8,23 \%. Embora este isômero tenha apresentado participação relevante na gordura do queijo, ele é considerado neutro quanto a sua ação sobre as LDL circulantes (Dietschy, 1998).
Tabela 4: Concentração de ácidos graxos do queijo Minas frescal obtido do leite de vacas F1 Holandês $x$ Zebu alimentadas com dietas contendo níveis crescentes de ureia

\begin{tabular}{|c|c|c|c|c|c|c|}
\hline \multirow[b]{2}{*}{ Componentes } & \multicolumn{4}{|c|}{$\begin{array}{l}\text { Níveis crescentes de PB na } \\
\text { forma de NNP }(\%)\end{array}$} & \multirow[b]{2}{*}{ CV (\%) } & \multirow[b]{2}{*}{$\hat{Y}$} \\
\hline & 0 & 0,92 & 1,84 & 2,77 & & \\
\hline \multicolumn{7}{|c|}{$\mathrm{mg} / \mathrm{g}$ de gordura } \\
\hline Saturados & 75,24 & 74,51 & 75,68 & 76,25 & 1,65 & 75,42 \\
\hline $\mathrm{C} 4: 0$ & 2,66 & 2,55 & 2,63 & 2,55 & 6,07 & 2,6 \\
\hline C6:0 & 2,15 & 2,08 & 2,14 & 2,10 & 3,9 & 2,12 \\
\hline C8:0 & 1,29 & 1,26 & 1,3 & 1,29 & 7,06 & 1,29 \\
\hline C10:0 & 2,99 & 2,89 & 3,01 & 2,99 & 9,02 & 2,97 \\
\hline C12:0 & 3,94 & 3,78 & 4,06 & 4,02 & 11,33 & 3,95 \\
\hline $\mathrm{C} 14: 0$ & 12,45 & 12,41 & 12,64 & 12,74 & 4,29 & 12,56 \\
\hline C15:0 Anteiso & 0,43 & 0,49 & 0,49 & 0,53 & 6,14 & 0,48 \\
\hline C15:0 & 1,02 & 1,16 & 1,16 & 1,15 & 18,91 & 1,12 \\
\hline C16:0 & 38,21 & 37,29 & 38,02 & 39,1 & 4,57 & 38,15 \\
\hline C17:0 & 0,51 & 0,52 & 0,52 & 0,51 & 7,00 & 0,51 \\
\hline \multirow{2}{*}{$\begin{array}{l}\text { C18:0 } \\
\text { Monoinsaturados }\end{array}$} & 8,23 & 8,39 & 8,29 & 7,84 & 16,09 & 8,19 \\
\hline & 22,06 & 22,83 & 21,86 & 21,45 & 5,36 & 22,05 \\
\hline C14:1 C9 & 1,15 & 1,1 & 1,16 & 1,16 & 15,51 & 1,14 \\
\hline C16:1 C9 & 1,88 & 1,84 & 1,9 & 1,93 & 7,35 & 1,89 \\
\hline C18:1 T10-T11-T12 & 0,63 & 0,73 & 0,64 & 0,57 & 31,85 & 0,65 \\
\hline C18:1 C9 & 15,77 & 16,54 & 15,54 & 15,22 & 6,92 & 15,77 \\
\hline \multirow{2}{*}{$\begin{array}{l}\text { C18:1 C11 } \\
\text { Poli-insaturados }\end{array}$} & 1,11 & 1,26 & 1,32 & 1,13 & 26,59 & 1,2 \\
\hline & 2,28 & 2,27 & 2,07 & 1,96 & 9,76 & 2,14 \\
\hline C18:2 C9 C12 & 1,30 & 1,29 & 1,14 & 1,11 & 15,73 & 1,21 \\
\hline C18:3 n3 & 0,43 & 0,41 & 0,38 & 0,38 & 12,56 & 0,4 \\
\hline C18:2 C9 T11(CLA) & 0,28 & 0,3 & 0,27 & 0,23 & 29,24 & 0,27 \\
\hline
\end{tabular}

$\mathrm{CLA}=$ Ácido linoleico conjugado

Dentre os ácidos graxos monoinsaturados (AGMI), o ácido predominante foi o oleico (18:1 C9) apresentando percentual de $15,77 \%$ e o total de AGMI de $22,05 \%$. O ácido graxo oleico (C18:1 C9) também é considerado na literatura científica como hipocolesterolêmico (Dietschy, 1998). O ácido linoleico (C18:2 C9 $\mathrm{C} 12$ ), com $1,21 \%$, foi o ácido graxo poli-insaturado (AGPI) predominante, enquanto o total de AGPI encontrado foi $2,14 \%$ (Tabela 4). Elevar a concentração de ácidos graxos insaturados é de grande importância, uma vez que estes são precursores da síntese endógena de CLA C18:2 cis-9 trans-11, que tem propriedades anticancerígenas, além de outras benéficas à saúde humana, como a redução de risco de doenças coronarianas e aterosclerose (Nudda et al., 2014).

A Tabela 5 apresenta os índices que indicam a qualidade nutricional do perfil lipídico relacionada com a saúde humana encontrados no queijo minas frescal produzido a partir de dietas com níveis crescentes de ureia. Como pode ser verificado, não 
houve influência $(P>0,05)$ da substituição do farelo de soja pela ureia na dieta das vacas sobre estes índices.

Tabela 5: Índice de aterogenecidade (IA), índice de trombogenecidade (IT), relação Hiper/Hipocolesterolêmicos, ácidos graxos desejáveis, relação de ácidos graxos poli-insaturados/ácidos graxos saturados (AGP) AGS) e relação ômega6/ômega3 do queijo minas frescal obtido do leite de vacas F1 (Holandês x Zebu) alimentadas com dietas contendo níveis crescentes de ureia e coeficiente de variação

\begin{tabular}{|c|c|c|c|c|c|c|}
\hline \multirow[b]{2}{*}{ Variáveis } & \multicolumn{4}{|c|}{$\begin{array}{l}\text { Níveis crescentes de PB na } \\
\text { forma de NNP }(\%)\end{array}$} & \multirow[b]{2}{*}{ CV (\%) } & \multirow[b]{2}{*}{$\hat{Y}$} \\
\hline & 0 & 0,92 & 1,84 & 2,77 & & \\
\hline IA & 4,09 & 3,88 & 4,16 & 4,31 & 7,43 & 4,11 \\
\hline IT & 5,16 & 4,9 & 5,22 & 5,39 & 5,65 & 5,17 \\
\hline $\begin{array}{l}\text { Hiper/ } \\
\text { Hipocolesterol }\end{array}$ & 2,09 & 1,98 & 2,12 & 2,22 & 7,95 & 2,1 \\
\hline AG desejáveis & 30,99 & 33,81 & 31,43 & 31,59 & 10,35 & 31,96 \\
\hline AGP/AGS & 0,03 & 0,03 & 0,03 & 0,03 & 10,08 & 0,03 \\
\hline ஸ6/డ33 & 14,45 & 13,63 & 14,41 & 13,94 & 14,39 & 14,11 \\
\hline
\end{tabular}

AGP/AGS = Ácidos graxos poli-insaturados/Ácidos graxos saturados; $\omega 6 /$ W3 = Relação ômega6/ômega3

No presente estudo, os IA e IT encontrados no leite foram em média 4,11\% e 5,17\%. De acordo com Turan et al. (2007), os IA e IT indicam o potencial de estímulo à agregação plaquetária, ou seja, quanto menores os valores de IA e IT, maior é a quantidade de ácidos graxos antiaterogênicos presentes em determinado óleo/gordura e, consequentemente, maior é o potencial de prevenção ao aparecimento de doenças coronarianas. Segundo Sousa Bentes et al. (2009), não há valores recomendados para os IA e IT em produtos lácteos, portanto, considera-se que quanto menor for o valor desses índices, mais favorável é o perfil de ácido graxo à saúde humana.

$\mathrm{O}$ índice relacionado com as razões entre ácidos graxos hiper e hipocolesterolêmicos $(\mathrm{HH})$ resultou em um valor médio de 2,10\%. Quanto menor a razão $\mathrm{HH}$, mais adequado nutricionalmente é o óleo ou a gordura. De acordo com SantosSilva et al. (2002), a relação HH constitui um índice que considera a atividade funcional dos ácidos graxos no metabolismo das lipoproteínas de transporte do colesterol plasmático, cujos tipo e quantidade estão relacionados com o maior ou menor risco de incidência de doenças cardiovasculares. Na literatura não há valores recomendados para o índice $\mathrm{HH}$ em relação aos produtos lácteos, porém, considera-se como referência o valor 2,0 \% atribuído aos produtos cárneos. Valores inferiores a 2,0 \% correspondem a produtos com composição de ácidos graxos desejável no aspecto nutricional, pois são compostos, em sua maior parte, de AG hipocolesterolêmicos e, consequentemente, reduzem o risco de doenças cardiovasculares. O índice relacionado com as razões entre $\mathrm{HH}$ constatado no presente trabalho resultou em valor médio de $2,10 \%$, mostrando que o queijo minas frescal obtido de leite de vacas F1 Holandês $x$ Zebu alimentadas com níveis crescentes de ureia apresenta uma composição de ácidos graxos muito próximo do valor desejável.

A razão AGPI/AGS abaixo de 0,45\% tem sido considerada como indesejável na dieta (Haug et al., 2007; Martin et al., 2006) por sua potencialidade na indução do aumento de colesterol sanguíneo. $\mathrm{O}$ valor médio encontrado neste estudo para essa variável foi de $0,03 \%$ ficando abaixo dos valores desejados.

Considerando a razão $\omega 6 / \omega 3$, valores abaixo de 4,0\% sugerem quantidades desejáveis na dieta para a prevenção de riscos cardiovasculares (Haug et al., 2007; Martin et al., 2006). A relação $\omega 6 / \omega 3$ encontrada no presente trabalho foi em média $14,11 \%$, resultado potencialmente superior às quantidades desejáveis.

A análise microbiológica do queijo teve como objetivo verificar se o produto estava dentro dos requisitos microbiológicos previstos pela Agência Nacional de Vigilância Sanitária (Brasil, 2001) para a realização da análise sensorial. Na análise dos micro-organismos do grupo dos coliformes, foram encontrados resultados de $2,68 \times 10^{3} \mathrm{NMP} / \mathrm{g}$ para coliformes a $35^{\circ} \mathrm{C}$ e 3 $x 10^{2} \mathrm{NMP} / \mathrm{g}$ para coliformes a $45^{\circ} \mathrm{C}$ ou micro-organismos termotolerantes. Dessa forma, os queijos encontravam-se dentro do limite tolerado para queijo de "muito alta umidade" (55\%), prevista pela legislação que é de no máximo $5 \times 10^{2}$ $\mathrm{NMP} / \mathrm{g}$, para coliformes a $45^{\circ} \mathrm{C}$, sendo então as amostras submetidas à análise sensorial. Em relação à contagem de mesófilos, o valor encontrado foi de $3,73 \times 10^{3} \mathrm{NMP} / \mathrm{g}$. Todavia, ressalta-se que não há exigência por parte da legislação vigente para este grupo de micro-organismos.

Os resultados do teste de aceitação geral do queijo minas frescal mostraram que não houve diferença significativa quanto à aceitação geral dos queijos dos diferentes tratamentos por parte dos provadores. Empregando-se a escala hedônica de nove pontos, constatou-se as seguintes pontuações, 7,24, $7,17,7$ e 6,83, para os queijos das respectivas dietas com níveis crescentes de ureia $(0,0,92,1,84$ e 2,77 \% de PB na forma de NNP). Na pontuação definida na escala hedônica, nos resultados mencionados, atribui-se ao queijo uma classificação: "gostei ligeiramente" para o valor 6,83 e "gostei moderadamente" para a média 7,24 . Os resultados encontrados para o teste de aceitação geral são considerados satisfatórios já que os mesmos aproximam-se muito do valor 9 (gostei extremamente). Além disso, a aceitação sensorial satisfatória do queijo minas frescal também pode ser explicada em função da tradição regional do consumo desse produto. Portanto, pode-se considerar que a total substituição do farelo de soja pela ureia na dieta de vacas, com produção média de $10 \mathrm{~kg}$ de leite dia $^{-1}$, com o intuito de reduzir custo de alimentação, não prejudica a aceitação do queijo minas frescal pelos consumidores.

\section{Conclusão}

De acordo com os resultados apresentados, a substituição total do farelo de soja pela ureia, com o intuito de reduzir os custos com alimentação, na dieta vacas F1 Holandês x Zebu, com produção de até $10 \mathrm{~kg}$ de leite corrigido para $3,5 \%$ de gordura dia $^{-1}$, não altera o rendimento, composição físicoquímica e o perfil de ácidos graxos do queijo minas frescal, assim como não influencia a preferência dos julgadores na aceitação sensorial. 


\section{Agradecimentos}

À FAPEMIG pelo auxílio financeiro; ao CNPq e CAPES pelo auxílio com bolsas. Ao INCT-Ciência Animal.

\section{Referências}

AGUIAR, A. C. R.; OLIVEIRA, C. R.; CALDEIRA, L. A.; ROCHA JUNIOR, V. R.; OLIVEIRA, S. J.; SOARES, C.; SILVA, D. A.; MENEZES, J. C. BORGES, L. D. A. Consumo, produção e composição do leite e do queijo de vacas alimentadas com níveis crescentes de ureia. Revista Brasileira de Ciência Veterinária, v. 20, n. 1, p. 37-42, 2013.

ANDREATTA, E.; FERNANDES, A. M.; SANTOS, M. V.; MUSSARELLI, C.; MARQUES, M.C.; GIGANTE, M. L.; OLIVEIRA, C. A. F. Quality of minas frescal cheese prepared from milk with different somatic cell counts. Pesquisa Agropecuária Brasileira, v. 44, p. 320-326, 2009.

AQUINO, A. A. BOTARO, B. G.; ALBERTO, C. S. S.; GIGANTE, M. L.; SANTOS, M. V. Efeito de níveis crescentes de uréia na dieta de vacas leiteiras sobre a composição e rendimento de fabricação de queijos minas frescal. Brazilian Journal Veterinary Research Animal Science, v. 46, n. 4, p. 273-279, 2009.

BENCHAAR, C.; PETIT, H. V.; BERTHIAUME, R.; OUELLET, D. R.; CHIQUETTE, J.; CHOUINARD P. Y. Effects of essential oils on digestion, ruminal fermentation, rumen microbial populations, milk production, and milk composition in dairy cows fed alfalfa silage or corn silage. Journal of Dairy Science, v. 90, p. 886-897, 2007.

BRASIL. Agência Nacional de Vigilância Sanitária. Resolução $R D C n^{\circ} 12$, de 02 de janeiro de 2001. Regulamento Técnico sobre padrões microbiológicos para alimentos. Diário Oficial da República Federativa do Brasil, Brasília, DF, 10 jan. 2001, Seção I, p. 45-53.

BRASIL. Ministério da Agricultura, Pecuária e Abastecimento. Métodos analíticos oficiais físico-químicos para controle de leite e produtos lácteos. Instrução Normativa $n^{\circ} .22$ de 14 de dezembro de 2006. Diário Oficial da União, Brasília, DF, 2006. Disponível em: <http://www.agricultura.gov.br>. Acesso em 18 fev. 2014.

BRASIL. Ministério da Agricultura, Pecuária e Abastecimento. Secretaria de Defesa Agropecuária. Departamento de Inspeção de Produtos de Origem Animal. Instrução Normativa $n^{\circ} 4$, de 01 de março de 2004. Diário Oficial da União, Brasília, DF, 2004. Disponível em: <http://www.agricultura.gov.br>. Acesso em 18 fev. 2014.

BRASIL. Ministério da Agricultura, Pecuária e Abastecimento. Secretaria de Defesa Agropecuária. Departamento de Inspeção de Produtos de Origem Animal. Instrução Normativa n. 62, de 26 de agosto de 2003. Oficializa os métodos analíticos oficiais para análises microbiológicas para controle de produtos de origem animal e água. Diário Oficial da União, Brasília, DF, 18 set. 2003. Disponível em: <http://www.agricultura.gov.br>. Acesso em: 18 fev. 2014

COSTA, R. G.; MESQUITA, I. V. U.; QUEIROGA, R. C. R. E.; MEDEIROS, A. N.; CARVALHO, F. F. R.; BELTRÃO FILHO, E. M. Características químicas e sensoriais do leite de cabras Moxotó alimentadas com silagem de maniçoba. Revista Brasileira de Zootecnia, v. 37, n. 4, p. 694-702, 2008.

DEPARTMENT OF HEALTH AND SOCIAL SECURITY. Nutritional aspects and cardiovascular disease: report on health and social subjects. HMSO, London, n. 46, p. 1-178, 1994.

DIETSCHY, J. M. Dietary fatty acids and the regulation of plasma low density lipoprotein cholesterol. Journal Nutrition, v. 2, n. 128, p. 444-448, 1998.
FERNANDES, M. F.; QUEIROGA, R. C. R. E.; MEDEIROS, A. N.; COSTA, R. G.; BOMFIM, M. A. D.; BRAGA, A. A. Características físico-químicas e perfil lipídico do leite de cabras mestiças Moxotó alimentadas com dietas suplementadas com óleo de semente de algodão ou de girassol. Revista Brasileira de Zootecnia, v. 37, n. 4, p. 703-710, 2008.

HAUG, A.; HØSTMARK, A. T.; HARSTAD, O. M. Bovine milk in human nutrition - a review. Lipids in Health and Disease, v. 6, p. 25, 2007.

LUCEY, J.; KELLY, J. Cheese yield. Journal of the Society of Dairy Technology, v. 47, n. 1, p. 1-14, 1994.

MARTIN, C. A.; ALMEIDA, V. V.; RUIZ, M. R.; VISENTAINER, J. E. L.; MATSHUSHITA, M.; SOUZA, N. E.; VISENTAINER, J. V. Ácidos graxos poliinsaturados ômega-3 e ômega-6: importância e ocorrência em alimentos. Revista Nutrição, v. 19, p. 761-770, 2006.

MEILGAARD, M.; CIVILLE, G. V.; CARR, B. T. Sensory evaluation techniques. Boca Raton: CRC Press, 1999. v. 2, 387 p.

NATIONAL RESEARCH COUNCIL-NRC. Nutrient requeriments of dairy cattle. 7th ed. Washington: NRC, 2001. $381 \mathrm{p}$.

NUDDA, A.; BATTACONE, G.; BOAVENTURA NETO, O.;

CANNAS, A.; FRACESCONI, A. H. D.; ATIZORI, A. S.; PULINA, G. Feeding strategies to design the fatty acid profile of sheep milk and cheese. Revista Brasileira Zootecnia, v. 43, n. 8, p. 445-456, 2014.

OLIVEIRA, J. S. Queijo: fundamentos tecnológicos. 2. ed. Campinas: Unicamp, 1986. $146 \mathrm{p}$.

SANTOS-SILVA, J.; BESSA, R. J. B.; SANTOS-SILVA, F. Effect of genotype, feeding system and slaughter weight on the quality of light lambs: Fatty and composition of meat. Livestock Production Science, v. 77, n. 2, p. 187-194, 2002.

SAS INSTITUTE. SAS/STAT User's guide. Version 9.1. Cary, NC, 2004.

SHACKELFORD, S. D.; MORGAN, J. B.; CROSS, H. R.; SAVELL, J. W.; Identification of threshold levels for warnerbratzler shear force in beef top loin steaks. Journal of Muscle Foods, v. 2, p. 289-296, 1991.

SILVA, N.; JUNQUEIRA V. C. A.; SILVEIRA, N. F. A.; TANIWAKI, M. H.; SANTOS, R. F.; GOMES, R. A. R. Manual de métodos de análises microbiológicas de alimentos. 4. ed. São Paulo: Livraria Varela. 2010.

SOUSA BENTES, A.; SOUZA, H. A. L.; MENDONÇA, X. M. F. D.; SIMÕES, M. G. Caracterização física e química e perfil lipídico de três espécies de peixes amazônicos. Revista Brasileira de Tecnologia Agroindustrial, Paraná, v. 3, n. 2, p. 97-108, 2009.

SOUZA, R. P. N.; SILVA, R. S. S. F. Estudo de custo e rendimento do processamento de queijo minas frescal. Ciências Tecnologia de Alimentos, v. 25, n. 1, p. 170-174, 2005.

TURAN, H.; SÖNMEZ, G.; KAYA, Y. Fatty acid profile and proximate composition of the thornback ray (Raja clavata, L. 1758) from the Sinop coast in the Black Sea. Journal Fisheries Science, v. 1. n. 2, p. 97-103, 2007.

ULBRICH, T. L. V.; SOUTHGATE, D. T. A. Coronary heart disease: seven dietary factors. Journal Lancet, v.338, n.19, p.985992, 1991.

VLAEMINCK, B.; FIEVEZ, V.; TAMMINGA, S.; DEWHURST, $R$. J.; VAN VUUREN, A.; DE BRABANDER, D. AND DEMEYER, D. Milk odd- and branched-chain fatty acids in relation to the rumen fermentation pattern. Journal of Dairy Science, v. 89, p. 3954-3964, 2006. 